\title{
Potential Benefits and Challenges in Applying Regional EIA: A Case Study of Special Investment Regions in India
}

\author{
Masoom Mallick ${ }^{1}$, Aditya Singh ${ }^{2}$ \\ ${ }^{1}$ Gujarat Industrial Development Corporation, Gandhinagar, India; ${ }^{2}$ University of Portsmouth, Portsmouth, UK. \\ Email: mmasoom5@gmail.com, aadigeog@gmail.com
}

Received November $6^{\text {th }}, 2013$; revised December $5^{\text {th }}$, 2013; accepted January $2^{\text {nd }}, 2014$

Copyright (C) 2014 Masoom Mallick, Aditya Singh. This is an open access article distributed under the Creative Commons Attribution License, which permits unrestricted use, distribution, and reproduction in any medium, provided the original work is properly cited. In accordance of the Creative Commons Attribution License all Copyrights (C) 2014 are reserved for SCIRP and the owner of the intellectual property Masoom Mallick, Aditya Singh. All Copyright @ 2014 are guarded by law and by SCIRP as a guardian.

\section{ABSTRACT}

Development is an ever growing process and its impact is often detrimental to environment which in turn may lead to adverse consequences for human life. Environment Impact Assessment (EIA) is an anticipatory and participatory environment management tool which helps in the decision-making process for different upcoming development projects by analyzing the environmental consequences of the action. The large scale projects like setting up of Special Investment Regions (SIR), Special Economic Zones (SEZ) and Industrial Estates (IE) have cumulative impacts on the environmental condition of the region. This paper intends to describe different practices of impact assessment and seeks to direct this debate towards the potential benefits of applying Regional EIA over the project specific EIA to capture the cumulative impact of large development projects like SIRs and IE on the environmental condition of the region and underline the challenges often faced during the study. Regional EIA is a new concept in India and the process of development of an SIR is different from the other industrial projects such as SEZ or IE. Unlike SEZ which comprises of only industrial activity, SIR also includes residential commercial and other amenities over an area of more than 100 square kilometers. Further, the implementation of Regional EIA in Indian context is also constrained by problem in baseline data collection and lack of exhaustive ecological and socioeconomic indicators for impact assessment and restricted use of state of art technologies such as Geographical Information System due to many factors such as cost involved and lack of awareness among consultants. The whole process of Regional EIA should be made rapid and more participatory.

\section{KEYWORDS}

Regional Environmental Impact Assessment (REIA); Special Investment Region (SIR); Special Economic Zone (SEZ); Cumulative Effects

\section{Introduction}

In 1960's, economic development was given more weightage over the environment. It was generally accepted that the benefits of economic development would be more than enough to compensate for any deterioration in environmental quality associated with these developments. During this period, the project review was mainly based on the technical/engineering and economic analysis. Environmental degradation and depletion of natural resources induced by the human activities later attracted steadily growing concerns and came into the picture in the United Nations conference held at Stock- holm in June 1972. This conference is widely recognized as the beginning of modern political and public awareness of global environmental problems wherein the focus was to provide a framework for the comprehensive consideration of the problems of human environment. In parallel with and following the Stockholm conference, there was a surge of policy making and institution building in the developed world.

The National Environment Policy Act (NEPA) 1969, which became effective on January 1, 1970, of the United States, was the first piece of legislation that dealt with cross-sectoral issues and launched the word Environment Impact Assessment (EIA) into the worldwide use. The 
act has been referred as the "Magna Carta for the Environment" in the United States [1]. During this period, basic principles, guidelines and procedures including the public participation were instituted. It has since then evolved considerably as it has been used increasingly in many countries around the world in the decision-making process. However, EIA, as it is practiced today, is being used as a decision-aiding tool rather than a decisionmaking tool.

In India, many of the development projects till as recently as the 1980's were implemented keeping in mind very little or no environmental concerns. The environmental issues came into the picture when a national committee on the environmental planning and coordination was set up under the $4^{\text {th }}$ five year plan (1969-1978). When till 1980, the subjects of environment and forest were the concern of Department of Science and Technology (DST) and Ministry of Agriculture (MOA), respectively. Later, the issues were formally attended by the Department of Environment (DoE) which was established in 1980 which was later upgraded to the Ministry of Environment and Forest (MoEF) in 1985.

The foundation of EIA in India was laid in (1976-77) when the planning commission asked Department of Science and Technology (DST) to examine the rivervalley projects from environmental angle. Later on, this was subsequently extended to cover those projects which required approvals from Public Investment Board. However, these were administrative decisions and lacked the legislative support. To make it mandatory from the legislative point of view, the Environment Protection Act (EPA) was enacted by MoEF, Government of India on $23^{\text {rd }}$ May 1986 which is known as Umbrella Act under which EIA notification, 1994 was enacted. The EIA notification (1994) made Environmental Clearance (EC) mandatory for expansion or modernization of any activity or for setting up new projects listed in Schedule 1 of the notification. Since then, there have been about twelve amendments made in the EIA notification of 1994 [2-4].

The overall goal of EIA is to encourage the consideration of environmental issues in the decision-making so to "ultimately arrive at actions which are more environmentally compatible". Later on, EIA became so important that even funding agencies like the World Bank and the Asian Development Bank (ADB) recognized the need of EIA or IEE (Initial Environmental Examination) depending upon the type of the project before granting loans. A number of bilateral agencies also have prescribed guidelines for the environmental assessment of projects for which they provide the financial assistance [5].

\section{EIA Practice in Developed and Developing Countries}

In developed countries like United States and European, there is a well framed EIA legislation to carry out EC for different projects whereas in developing countries there is lack of formal EIA legislation. On the other hand, in many African countries, EIA is not even mandatory. In developed countries, there is active involvement of people/competent authority/government agencies at initial as well as later stages of EIA whereas in developing countries, there is limited involvement of public/government agencies during initial phases of EIA which results into poor prediction of impact. In developed countries, there is integrated approach to wherein social and health aspects are taken into account whereas in developing countries, there is less stress on social and health aspects. The screening process of EIA in developed countries is decided by competent/authorized agencies whereas in developing countries, the screening process is decided as per the activity mentioned in EIA notification without taking into account the threshold value of pollution load [6].

\section{Different Paradigms of EIA}

Tracing the environmental movement from its origin in the 1960's to the present day as it appears mainly three main concepts has evolved.

\subsection{EIA at the Project Levels}

In many countries in the world where EIA is in place, development projects undergo an environmental examination prior to being given clearance to establish and operate. Present EIA practice in India is restricted to project level, which recommends appropriate mitigation measures or monitoring or management plans in the project itself.

\subsection{From Project to Regional EIA}

The emphasis in environmental impact studies in the early 1970's was on the physical-chemical and biological environments. However, added attention was given to the cultural and socioeconomic environments as the decade progressed. In late 1970's, the emergence of multidimensional character in the project level EIA came into picture which involved inclusion of the social dimension into the process. Social Impact Assessment (SIA) analysis and risk analysis was incorporated into the process of EIA [7]. This turn in the concept of EIA was the result of recognition of the fact that the different components of the environment are interdependent. It was later on realized that the scope and level of EIA needs to be expanded further where regional plans/master plans or development plans are to be considered. An EIA, thus, can be performed at various levels depending upon the scale of the development activity. In a large industrial estate, for example, while the individual industrial emission, 
effluent discharge etc. may be within the permissible limit, the cumulative effect of the emission or effluent discharge of different industrial units may lead to deterioration of overall air/water quality in the region.

This is the fairly latest extension of the impact assessment which investigates the combined effects of the multiple activities instead of the effect of a specific development project.

\subsection{Policy Level Strategic EIA}

The increasing scale of the global environmental problems was an indication that the environmental deterioration was accelerating and it is not restricted to a specific project or region. By late 1980's and early 1990's, the experience of EIA over projects and regional plans led to the recognition that EIA of policies should be conducted on a strategic level. Strategic Environmental Assessment (SEA), basically inquires about the impact of an existing plans, policies and programs on environment. It can be applied both at the level of broad policy initiatives and to more concrete programs and plans having physical and spatial reference [8].

If policies at a generic level are evolved on an environmentally sound basis then associated regional plans and projects are expected to cause least conflict between regional and local environmental priorities and issues.

\section{Need of Regional EIA for SIRs}

Regional EIA is more than expanding the boundaries of EIA "up" to a higher tier or "out" to encompass a broader geographic area, rather it represents a different way of approaching the relationship between environment and development decision making at a regional scale. A project level impact assessment is limited to a specific area and it does not ask whether the proposed undertaking is the most appropriate form of development or whether the cumulative effects of such development are in conflict with broader environmental goals or desired future conditions. It disregards the cumulative impacts i.e. deforestation, depletion of the ozone layer, biodiversity decline etc. No single project can be considered responsible for the problems; however they do occur due to the combination of several impact sources. When projects are assessed individually, not much attention is paid to other developments (existing or planned) affecting the same area, consequently the decision makers are masked the true nature of the problem under analysis and are asked to assess the acceptability of individual impacts. Such impacts often appear negligible despite their potentially harmful cumulative effect (e.g. loss of little woodland due to the construction of an infrastructure) $[9,10]$.

SIRs as compared to SEZ have larger spatial extent and is not merely only export oriented. Instead, they offer a range of other services and comprises of residential, institutional etc. along with the industrial estates. Gujarat is one of the first states to promote SIRs in India [11-13]. The concept of SIR came into the picture to control the haphazard growth of industries outside existing notified Industrial Estates (IE) for planned development. These SIRs are having large spatial extent and includes residential, commercial and other amenities apart from existing Industrial Estate. Thus, for such a large area containing different land uses Regional EIA is needed for assessing the cumulative impact of the proposed industries on the region as a whole. These SIRs are undergoing regional EIA study and approaching MoEF for EC under the category $7(\mathrm{c})^{1}$.

\section{Challenges Being Faced during the Study}

\subsection{SIR Being a New Concept as per the EIA Notification}

SIRs came into existence in 2009 with the advent of Special Investment Region Act, 2009 [13]. As per the EIA notification 2006 and 2009 under activity 7(c), only terms like Industrial Estates/Export Processing Zones/ Special Economic Zones are mentioned. SIR is a new concept which is nowhere mentioned in the notification. Thus, the project proponent approaching MoEF for EC under category 7 (c) is required to give clear-cut picture of difference between SEZ and SIR. Also MoEF is not clear about the process of development of these SIRs as they are being developed through Town Planning Schemes (TPS) where there is no acquisition of land. Through this scheme, a small portion of land is taken for developing trunk infrastructure and the rest major portion is returned to owners as the final plot.

\subsection{Delineation of the Boundary of an SIR}

The concept of SIR came into existence to restrict the haphazard growth of the industries beyond the existing boundary of notified IE. The state of Gujarat is the first state among Indian states to have passed SIR ordinance [14]. These IE have been recognized as Industrial Nodes along the Delhi-Mumbai Industrial Corridor. The SIRs are generally spread over an area of more than 100 square kilometers. The boundary of an SIR includes not only full-fledged existing industrial areas but also industries/IEs which are not yet established but have already taken NOC and EC from the concerned authorities. Apart from that, it also includes areas (residential or industrial) under development for which zonal plans has been made under broader development plans. An EIA study being

${ }^{1}$ As per the EIA notification 2006 from MoEF category 7(c) is for Industrial Estates/ Parks/Complexes/Areas, Export Processing Zones (EPZs), Special Economic Zones (SEZs), Biotech Parks, Leather Complexes. 
carried out for such area development projects comprises of both situations (existing and proposed) within the SIR boundary. The baseline data collection of existing industrial units is easily generated from primary survey as well as secondary sources like audit reports of individual industries. However, the baseline data generation for the proposed industries is a major challenge being faced by consultants as it is entirely based on assumptions taking into account different case studies from India or abroad.

\subsection{Comprehensive Baseline Data Collection}

Regional EIA study as compared to project level EIA takes more time as it entails comprehensive data collection which requires setting up adequate number of monitoring stations for a considerable period of time (for instance, pre-monsoon, monsoon and post-monsoon periods) in order to assess the cumulative effects in the whole region. Since the validity of the Terms of Reference (ToR) issued by MoEF for conducting the EIA study is only for two years, it is often difficult to complete the entire study within this given time period. The delay in baseline data collection compels individual industries within proposed SIR to approach the ministry for EC without taking into consideration the conditions of EC of the region as a whole. On the other hand, the SIR, at the same time, also undergoes EC from the Ministry without taking in-principal approval from Individual Units. This defeats the purpose of obtaining EC for the SIR as a whole.

\subsection{Insufficient Baseline Data for Impact Prediction}

Insufficient baseline data is a major challenge being faced by consultants while preparing good quality EIA reports. Lack of sampling networks and ill-defined sampling and analysis procedures also add to the problem of inconsistency. Although all major industries submit halfyearly monitoring data to State Pollution Control Board (SPCB), but the reliability of such data is doubtful. Therefore, it is very hard to predict the pollution potential for proposed industries.

Additionally, the lack of proper guidelines on the use of available modeling approaches put a question mark on their application to the Indian conditions and on their level of accuracy in predictions. Most of the mathematical models being used are not developed for Indian conditions, so validation is necessary each time, thus the accuracy of modeling depends on knowledge and expertise of the analyst [15]. EIA practice in India still considers impacts of individual activity/projects and the cumulative impact of the individual activity on the whole SIR region is a major challenge before consultant as it requires comprehensive baseline data collection.

\subsection{Environment Management Plan (EMP)}

EMP is one of the crucial parts of any EIA study wherein detail description is needed for proper implementation of the same. However, for large projects, it is often difficult to provide a detailed description. For example, the greenbelt development is one of the mitigation measures to reduce the adverse impact of pollution on the environment but it is often quite challenging to mention in the EIA report the type of plants to be planted considering the type of soil, agro climatic region and the type of pollutant emitted by the industry. Also, the total cost for implementing the mitigation plan is often hard to work out.

\subsection{Public Hearing Proceedings}

Earlier, there was no accreditation of consultants for sector specific projects, as a result of which the quality of EIA reports deteriorated. At a later stage, the accreditation of these consultants started through National Accreditation Board for Education and Training (NABET). Generally, for large scale projects, only sector specific NABET accredited consultants can carry out EIA study. These consultants are based anywhere in India and thus language constrain is the main problem faced by these consultants during public hearings proceeding as the executive summary and presentations are to be made available in local language for the convenience of the local people residing in the project area. Also, during the proceedings, it is hard to convince people regarding the project as they are very often ignorant about the concept. What actually happens in such area development projects is that the land is acquired from people and is developed through town planning schemes wherein some percentage of land is deducted for developing trunk infrastructure like road, street light, storm water drainage etcetera and the remaining major portion is given to the owner of land as a final plot of the land.

\subsection{Lack of Exhaustive Ecological and Socioeconomic Indicators for Impact Assessment}

Ecological and socioeconomic assessments are often marginalized within the impact study. One of the reasons for such marginalization could be lack of a common framework to support the impact assessment on ecological and socioeconomic components. Only a few analyses can be considered as standard and are found to have been applied in most of the studies. In general, there does not exist a common type of data, a common way of processing and organizing the information, of selecting the evaluation criteria, of expressing the impacts and so on. Contrary to this, air or noise pollution assessments ap- 
pear to be much more structured. They follow well- established procedures that guide the entire assessment right from data collection to discussion of the relevance of the impacts.

\subsection{Restricted Use of Geographic Information System (GIS) for Impact Prediction}

GIS is a tool which can be applied for a project where the spatial distribution of impact is relevant. The application of this software is restricted to wider use mainly because of cost associated with the development of GIS database. However, the cost of the development of GIS database is actually negligible when compared with the cost of impact mitigation measures [16]. It is a significant tool which can be used to make decision making process rapid and spatially accurate. Currently, even the MoEF desires to have a satellite imagery based land use classification for about three consecutive years for any project area. By doing this, it want to ensure that the green areas and drainage pattern are not adversely affected by the proposed activity in the study region. However, the fact of the matter is that not many EIA consultants are using GIS during impact prediction probably because they are not familiar with the utility of the software in this field.

\section{Conclusions}

Regional EIA came into the light to address the cumulative impact of upcoming projects on the whole region. It is significant especially for the projects having large spatial extent which consists of industrial estates as well as other areas such as residential, commercial and other like, for example, SIR and large industrial estates which can have irreversible impacts on the region as a whole. However, the different upcoming industries in the region approach MoEF for EC as per the schedule of list of projects or activities requiring prior EC mentioned in EIA notification 2006 and 2009 and these projects are not taking into consideration the terms and condition on which the region as a whole is approaching for EC to MoEF. Thus, to make Regional EIA more effective for such large area projects like SIR, it is necessary to make the process rapid so that different upcoming industries can come up with the prior terms and condition given by MoEF for sustainable development.

The whole process of Regional EIA should be made more participatory so that people can become aware of the mechanism on which these area development projects/SIR are developing. Also, the application of the new tools like GIS should be broaden for impact prediction which is based on the spatial distribution of impacts. Efforts should also be targeted to include environmental conservation concerns at policy and planning level so that the environmental factors can be taken into consid- eration well in advance at the policy level. As per the new environment ministry policy for the national manufacturing and investment zone (NMIZs), the individual units within the proposed NMIZs will be exempted from public hearings, once a public hearing has been conducted for the entire NMIZ, provided that these zones are notified as industrial estates by the state governments concerned. Thus, this will help in expediting the process of EC of the whole region which will facilitate to address the environmental issues in advance for sustainable development.

\section{REFERENCES}

[1] R. W. Peterson, "The Environmental Movement in the United States,” In: L. R. Rockwood, Ed., Foundations of Environmental Sustainability: The Coevolution of Science and Policy, Oxford University Press, Inc., New York, 2008, pp. 31-41.

http://dx.doi.org/10.1093/acprof:oso/9780195309454.003. $\underline{0002}$

[2] Ministry of Environment and Forests, "The Environment (Protection) Act Notification-Regarding New Towns and Industrial Estates. S.O. 801 (E)," Ministry of Environment and Forest, Government of India, New Delhi, 1986.

[3] Ministry of Environment and Forests, "The Environment Impact Assessment Notification. S.O.60 (E),” Ministry of Environment and Forest, Government of India, New Delhi, 1994. http://envfor.nic.in/legis/eia/so-60(e).html

[4] Ministry of Environment and Forests, "The Environment Impact Assessment Notification S.O.1533 (E),” Ministry of Environment and Forest, Government of India, New Delhi, 2006. http://envfor.nic.in/legis/eia/so1533.pdf

[5] L. W. Canter, "Environmental Impact Assessment,” McGraw-Hill, New York, 1995.

[6] C. Wood, "Environmental Impact Assessment in Developing Countries: An Overview,” 2003. http://www.sed.man.ac.uk/research/iarc/ediais/pdf/Wood. pdf

[7] B. K. Dutta and S. Bandyopadhyay, "Environmental Impact Assessment and Social Impact Assessment: Decision Making Tools for Project Appraisal in India,” International Journal of Human and Social Sciences, Vol. 5, No. 6, 2010, pp. 350-355.

[8] R. Therivel, "Strategic Environmental Assessment in Action,” Earthscan, London, 2004.

[9] L. McCold and J. Holman, "Cumulative Impacts in Environmental Assessments: How Well Are They Considered?” Environmental Professional, Vol. 7, No. 1, 1995. http://www.osti.gov/scitech/biblio/31819

[10] R. K. Burris and L. W. Canter, "Cumulative Impacts Are Not Properly Addressed in Environmental Assessments,” Environmental Impact Assessment Review, Vol. 17, No. 1, 1997, pp. 5-18.

http://dx.doi.org/10.1016/S0195-9255(96)00082-0

[11] A. Agrawal, "Special Economic Zones: Revisiting the 
Policy Debate,” Economic and Political Weekly, Vol. 41, No. 43, 2006, pp. 4533-4536.

[12] M. R. Mary and S. Sindhuja, "Special Economic Zones in India,” In: M. Soundarapandian, Ed., Development of Special Economic Zones in India, Concept Publishing Company, New Delhi, 2012.

[13] S. Latha and A. S. Sundan "Special Economic Zones in India: A Boon or Bane,” In: M. Soundarapandian, Ed., Development of Special Economic Zones in India, Concept Publishing Company, New Delhi, 2012, pp. 250-268.

[14] Gujarat Industrial Development Corporation, "Special Investment Region Act, 2009,” Government of Gujarat,
Gujarat, 2009.

http://www.gidb.org/cms.aspx?content_id=95

[15] R. Paliwal, "EIA practice in India and Its Evaluation Using SWOT Analysis,” Environmental Impact Assessment Review, Vol. 26, No. 5, 2006, pp. 492-510. http://dx.doi.org/10.1016/j.eiar.2006.01.004

[16] P. Antunes, R. Santos and L. Jordao, "The Application of Geographical Information Systems to Determine Environmental Impact Significance,” Environmental Impact Assessment Review, Vol. 21, No. 6, 2001, pp. 511-535. http://dx.doi.org/10.1016/S0195-9255(01)00090-7 